\title{
Chelating Fabrics Prepared by an Organic Solvent-Free Process for Boron Removal from Water
}

\author{
Hiroyuki Hoshina, Jinhua Chen *(D), Haruyo Amada and Noriaki Seko
}

check for updates

Citation: Hoshina, H.; Chen, J.; Amada, H.; Seko, N. Chelating Fabrics Prepared by an Organic Solvent-Free Process for Boron Removal from Water. Polymers 2021 13, 1163. https://doi.org/10.3390/ polym13071163

Academic Editor: George Z. Kyzas

Received: 29 March 2021

Accepted: 3 April 2021

Published: 5 April 2021

Publisher's Note: MDPI stays neutra with regard to jurisdictional claims in published maps and institutional affiliations.

Copyright: (C) 2021 by the authors. Licensee MDPI, Basel, Switzerland. This article is an open access article distributed under the terms and conditions of the Creative Commons Attribution (CC BY) license (https:/ / creativecommons.org/licenses/by/ $4.0 /)$.
Department of Advanced Functional Materials Research, Takasaki Advanced Radiation Research Institute Quantum Beam Science Research Directorate, National Institutes for Quantum and Radiological Science and Technology, 1233 Watanuki-machi, Takasaki, Gunma 370-1292, Japan; hoshina.hiroyuki@qst.go.jp (H.H.); amada.haruyo@qst.go.jp (H.A.); seko.noriaki@qst.go.jp (N.S.)

* Correspondence: chen.jinhua@qst.go.jp

\begin{abstract}
A chelating fabric was prepared by graft polymerization of glycidyl methacrylate (GMA) onto a nonwoven fabric, followed by attachment reaction of N-methyl-D-glucamine (NMDG) using an organic solvent-free process. The graft polymerization was performed by immersing the gammaray pre-irradiated fabric into the GMA emulsion, while the attachment reaction was carried out by immersing the grafted fabric in the NMDG aqueous solution. The chelating capacity of the chelating fabric prepared by reaction in the NMDG aqueous solution without any additives reached $1.74 \mathrm{mmol} / \mathrm{g}$, which further increased to above $2.0 \mathrm{mmol} / \mathrm{g}$ when surfactant and acid catalyst were added in the solution. The boron chelation of the chelating fabric was evaluated in a batch mode. Fourier transform infrared spectrophotometer (FTIR) was used to characterize the fabrics. The chelating fabric can quickly chelate boron from water to form a boron ester, and a high boron chelating ability close to $18.3 \mathrm{mg} / \mathrm{g}$ was achieved in the concentrated boron solution. The chelated boron can be eluted completely by $\mathrm{HCl}$ solution. The regeneration and stability of the chelating fabric were tested by 10 cycles of the chelation-elution operations. Considering the organic solvent-free preparation process and the high boron chelating performance, the chelating fabric is promising for the boron removal from water.
\end{abstract}

Keywords: chelating fabric; boron removal; nonwoven fabric; radiation; graft polymerization; $N$-methyl-D-glucamine (NMDG)

\section{Introduction}

The boron in seawater is about $4.5 \mathrm{mg} / \mathrm{L}$, while in rivers it ranges from 0.3 to $100 \mathrm{mg} / \mathrm{L}$. In Japan, the boron concentration in some hot-spring water even exceeds $100 \mathrm{mg} / \mathrm{L}$. In natural water, it exists in the form of undissociated boric acid, which is a weak acid as shown in Scheme 1. The pKa of boric acid at room temperature is 9.24. Boric acid in natural water comes from the leaching of soils and rocks, as well as the wastewater from the glass/ceramic and metallurgy industries [1]. In an alkali solution it forms a borate salt, while in vicinal diol compound solution it forms boron ester.

The boron in water is of special concern because of its possible toxic effects on humans, animals, and plants. According to the WHO guidelines in 2011, boron in drinking water must not exceed $2.4 \mathrm{mg} / \mathrm{L}$. Considering its impact on crops, boron in irrigation water is strictly regulated by many countries to be less than $0.5 \mathrm{mg} / \mathrm{L} \mathrm{[2-4].}$

The low-cost removal of boron from water has attracted considerable scientific interest $[5,6]$. Chemical precipitation is not suitable for removing trace boron from water. Ion-exchange resin is ineffective because boric acid exists as an unassociated compound in water. Membrane separation technologies, such as reverse osmosis membranes, are inadequate for rejecting boron because of the small size and neutral properties of the boric acid $[7,8]$. Adsorption methods using activated carbon, metal oxides, and other adsorbents for boron removal are also inefficient because of their low boron-adsorption [9]. 


$$
\begin{aligned}
& \mathrm{B}(\mathrm{OH})_{3}+\mathrm{H}_{2} \mathrm{O} \leftrightarrows \mathrm{B}(\mathrm{OH})_{4}^{-}+\mathrm{H}^{+} \quad \mathrm{pKa}=9.24 \\
& \mathrm{~B}(\mathrm{OH})_{3}+\mathrm{OH}^{-} \rightarrow \mathrm{H}_{2} \mathrm{BO}_{3}^{-}+\mathrm{H}_{2} \mathrm{O} \\
& \mathrm{B}(\mathrm{OH})_{3}+\frac{\mathrm{OH}_{\mathrm{OH}}}{\mathrm{T}} \underset{\mathrm{O}}{\mathrm{O}}+\mathrm{H}_{2} \mathrm{O}+\mathrm{H}^{+} \\
& \mathrm{HO}^{\mathrm{B}} \mathrm{OH}
\end{aligned}
$$

Scheme 1. Possible reactions of boric acid in water.

Recently, chelating resins having vicinal diol groups, such as Amberlite ${ }^{\circledR}$ IRA743 and DIAION ${ }^{\circledR}$ CRB05, have been specifically designed for boron removal [10]. These chelating resins are composed of polystyrenic microporous frameworks and $\mathrm{N}$-methyl$D$-glucamine (NMDG) moieties. The boron removal is based on the chelation reaction shown in Scheme 1, Equation (3), where boric acid is chelated by the vicinal diol to form a stable five- or six-membered ring boron ester and release a proton [11-13]. The other frameworks, such as poly(glycidyl methacrylate-co-methyl methacrylate) [3], poly(glycidyl methacrylate-co-trimethylolpropane trimethacrylate) [14], poly(chloromethyl styrene-codivinylbenzene) [7,15], and cellulose [16], have also been attached with the NMDG moieties to prepare the chelating resins for boron removal. These chelating resins are in the form of beads or particles, and are suitable for use in the column mode. Their boron chelating ability is strongly affected by the chelating capacity of the resins $[13,17]$, and is hardly affected by the $\mathrm{pH}$ in a wide region of 4.0-8.0 and ionic strength of the aqueous solution $[15,18]$. In an acidic medium with a $\mathrm{pH}$ lower than 2.0, the chelated boron can be eluted according to the reverse reaction shown in Scheme 1, Equation (3). However, owing to their high porosity and crosslinking, these chelating resins are fragile and should be transported and stored in a water-swollen state.

On the other hand, nonwoven fabrics are easy to manufacture and have been widely used in the industry. As a fibrous porous medium nonwoven fabric has a high specific surface area. The phenomenon of liquid or gas transport through it has been well studied [19]. The polymeric nonwoven fabric can be chemically modified and converted into functional materials for water treatments [20]. Herein, a chelating fabric with NMDG moieties was designed. The chelating fabric can be used in both batch and column modes and transported and stored in the dry state [21]. For this purpose, glycidyl methacrylate (GMA)-grafted fabric is used as a framework to attach the NMDG moieties. The grafted fabric was prepared by radiation grafting the GMA onto a polyethylene-coated polypropylene (PE/PP) nonwoven fabric. Radiation grafting is an effective method to modify existing materials in any form of fiber, film, and fabric, giving them new properties such as reactivity, hydrophilicity, and conductivity [22,23]. The PE/PP nonwoven fabric has many advantages, including low cost, high mechanical strength, and easy radiation grafting [23-25]. The GMA monomer has vinyl groups and active epoxy rings. The former gives it high graft polymerizability, while the latter gives it high reactivity to introduce various new functions [26-30].

The attachment of NMDG moieties onto the GMA-grafted fabric is based on the substitution reaction of amine with the epoxy ring. The reaction was carried out in a heterogeneous system, wherein NMDG is dissolved in the solution, and the GMA-grafted fabric is in the solid state. Therefore, the reaction is significantly affected by the diffusion of NMDG into the fabric and the steric structure of the reactants [31,32]. Acids and bases can accelerate the reaction or increase its selectivity [33]. Until now, the reaction of GMAgrafted fabric with NMDG was carried out in mixture solvents such as 1,4-dioxane and water [22]. The organic solvent 1,4-dioxane enhances the affinity of the reaction solution to the fabric, while water improves the solubility of NMDG in the solution. In this solution more than $80 \%$ of the epoxy rings can be converted to NMDG moieties [34-36]. However, the use of organic solvents is harmful to the environment and human health. In this study, we carried out the attachment reaction in NMDG aqueous solution without the use of organic solvents. This attachment reaction in an organic solvent-free process has rarely been reported. This may be due to the low affinity of the GMA-grafted fabric to the 
aqueous solution and the low reactivity. To address these concerns, we used surfactants and acid/base catalysts to accelerate the reaction. The boron chelation of the resulting chelating fabric was evaluated in batch mode in a boron aqueous solution.

\section{Experimental}

\subsection{Materials}

The PE/PP nonwoven fabric was obtained from Kurashiki Textile Manufacturing Co., Ltd., Kurashiki, Japan. The thickness of the fabric was about $0.5 \mathrm{~mm}$, and the diameter of the fabric fiber was about $13 \mu \mathrm{m}$. The chemical reagents of GMA, NMDG (also known as meglumine or methylglucamine), and boric acid $\left(\mathrm{B}(\mathrm{OH})_{3}\right.$ or $\left.\mathrm{H}_{3} \mathrm{BO}_{3}\right)$ were purchased from Fujifilm Wako Pure Chemical Corporation, Tokyo, Japan, and were used as-received. Three surfactants, polyoxyethylene sorbitan monolaurate (POSM, or Tween $\left.{ }^{\circledR} 20\right)$, sodium ndodecyl sulfate (SDS), and n-octyl trimethylammonium bromide (OTBr), along with $\mathrm{KOH}$ and $\mathrm{HCl}$ solutions, methanol, and 1,4-dioxane, were purchased from Kanto Chemical Co., Inc., Tokyo, Japan. The resistivity of water used for the washing and preparation processes was higher than $18.0 \mathrm{M} \Omega \mathrm{cm}$. The concentrations of monomer and NMDG solutions were presented in the form of weight percentage, and the concentrations of the boron aqueous solutions were presented as $\mathrm{mg} / \mathrm{L}$.

\subsection{Preparation of Grafted Fabric}

Scheme 2 shows the preparation process and the boron chelation image of the chelating fabric. For the preparation of GMA-grafted fabric, the PE/PP nonwoven fabric (14.06 g) was cut into $3.5 \mathrm{~cm} \times 6.0 \mathrm{~cm}$ slices and placed into a three-necked reaction flask. The flask was vacuumed, filled with nitrogen, and then placed in a Co-60 irradiation room for gamma-ray irradiation. The oxygen was completely removed to avoid the generation of peroxide during irradiation. The irradiation dose rate was $1.5 \mathrm{kGy} / \mathrm{h}$, and the total irradiation dose was $24 \mathrm{kGy}$. After irradiation, the flask was filled with GMA emulsion to completely immerse the fabric slices. The GMA emulsion was prepared by ultrasonic dispersion of a mixture of $40 \mathrm{~g}$ GMA, $4 \mathrm{~g}$ POSM surfactant, and $756 \mathrm{~g}$ water for $30 \mathrm{~min}$ before use. The flask was then placed in a bath at $40{ }^{\circ} \mathrm{C}$ for $4 \mathrm{~h}$ to initiate the graft polymerization. During grafting, nitrogen was bubbled into the emulsion at a rate of $5 \mathrm{~mL} / \mathrm{min}$ to prevent oxygen from entering. After grafting, the fabric slices were thoroughly washed with water and methanol, and then dried in an oven at $60^{\circ} \mathrm{C}$ for more than $24 \mathrm{~h}$. Finally, a GMAgrafted fabric was obtained. The weight of the dry GMA-grafted fabric was $39.30 \mathrm{~g}$, which corresponds to a degree of grafting of $179.5 \%$ and an epoxy density of $4.52 \mathrm{mmol} / \mathrm{g}$.

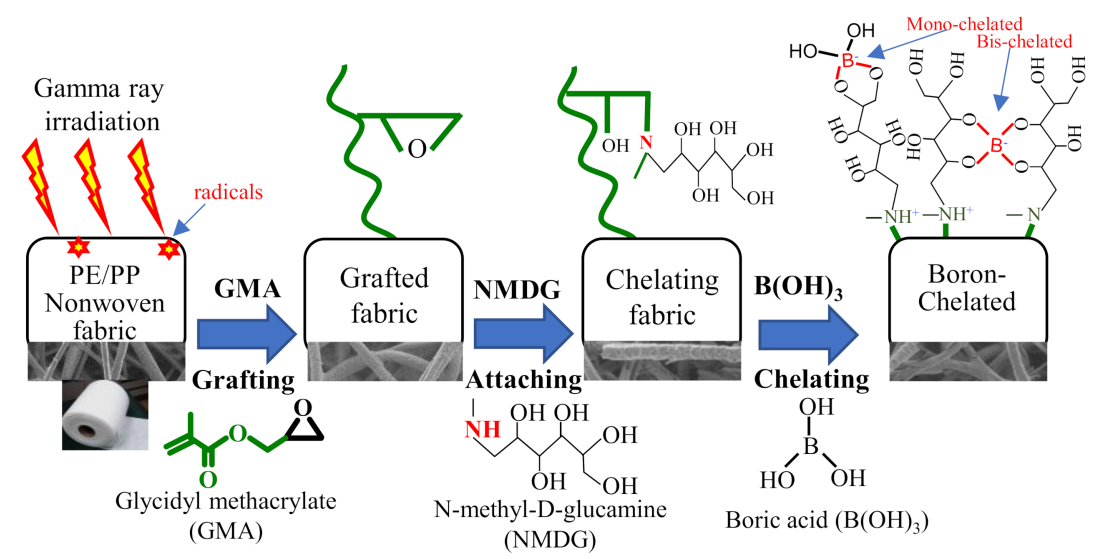

Scheme 2. Preparation and boron chelation image of chelating fabric.

\subsection{Preparation of Chelating Fabric}

For the preparation of chelating fabric, the GMA-grafted fabric was immersed into an NMDG solution at $80{ }^{\circ} \mathrm{C}$ to bring about a substitution reaction between the epoxy 
rings and NMDG molecules. The reaction was fixed at $80{ }^{\circ} \mathrm{C}$ and was investigated for up to $20 \mathrm{~h}$. After reaction, the fabric was removed and washed thoroughly with methanol and water, and dried in an oven at $60{ }^{\circ} \mathrm{C}$ for $24 \mathrm{~h}$. Thus, a chelating fabric with NMDG moieties was obtained. The conversion of epoxy rings to NMDG moieties and the chelating capacity (density of NMDG moieties) of the chelating fabric were calculated using the following equations.

$$
\begin{aligned}
& \text { Conversion }(\%)=\left(\mathrm{W}_{\mathrm{a}}-\mathrm{W}_{\mathrm{g}}\right) / \mathrm{M}_{\mathrm{NMDG}} /\left(\mathrm{D}_{\mathrm{e}} \times \mathrm{W}_{\mathrm{g}} / 1000\right) \times 100 \\
& \text { Chelating capacity }(\mathrm{mmol} / \mathrm{g})=\left(\mathrm{W}_{\mathrm{a}}-\mathrm{W}_{\mathrm{g}}\right) / \mathrm{M}_{\mathrm{NMDG}} /\left(\mathrm{W}_{\mathrm{a}} / 1000\right)
\end{aligned}
$$

where $W_{a}(\mathrm{mg})$ and $W_{g}(\mathrm{mg})$ are the weights of the GMA-grafted fabric after and before the attachment reaction, respectively; $\mathrm{M}_{\mathrm{NMDG}}(195.2 \mathrm{~g} / \mathrm{mol})$ is the molecular weight of NMDG; and $D_{e}(4.52 \mathrm{mmol} / \mathrm{g})$ is the epoxy density in the GMA-grafted fabric. We confirmed that the difference is very small for the chelating capacity under a same reaction condition. Therefore, only one experiment was performed for each condition to obtain the chelating capacity.

\subsection{Characterization}

Fourier transform infrared spectrophotometer (FTIR) in attenuated total reflectance (ATR) mode (Spectrum One, PerkinElmer, Inc., Tokyo, Japan) was used to analyze the fabric samples. The scanning range and resolution were $600-3800 \mathrm{~cm}^{-1}$ and $4.0 \mathrm{~cm}^{-1}$, respectively.

\subsection{Evaluation of the Chelating Fabric}

For the evaluation of the chelating fabric, the chelating fabric (about $100 \mathrm{mg}$ ) was immersed in a boron aqueous solution $(35 \mathrm{~mL}$ ) in a glass bottle and was shaken at a rate of $150 \mathrm{rpm}$ at $25^{\circ} \mathrm{C}$, during which the boron was chelated by vicinal diol of the fabric. The chelating capacity of the chelating fabric is $2.15 \mathrm{mmol} / \mathrm{g}$. From the viewpoint of practical use, boron aqueous solution was prepared by dissolving boric acid in deionized water without further adjusting the $\mathrm{pH}$ and ionic strength $[10,30]$. After chelation, the chelating fabric was immersed in $0.1 \mathrm{M} \mathrm{HCl}$ for boron elution. The chelating fabric was then washed thoroughly with $0.1 \mathrm{M} \mathrm{KOH}$ and water for regeneration.

The boron concentrations were detected by an ICP-OES system (Optima 8300, PerkinElmer, Inc., Tokyo, Japan). The samples were filtered through a $0.45 \mu \mathrm{m}$ filter and then diluted with a 10 -fold volume of $0.5 \% \mathrm{HNO}_{3}$. The amount of boron chelation was calculated using the following equation.

$$
\text { Boron chelation }(\mathrm{mg} / \mathrm{g})=\left(\mathrm{C}_{0}-\mathrm{C}_{\mathrm{i}}\right) \times \mathrm{V}_{\mathrm{a}} / \mathrm{W}_{\mathrm{a}}
$$

where $\mathrm{C}_{0}$ and $\mathrm{C}_{\mathrm{i}}$ are the boron concentrations $(\mathrm{mg} / \mathrm{mL})$ of the solution before and after chelation, respectively; $\mathrm{V}_{\mathrm{a}}(\mathrm{mL})$ is the volume of the boron aqueous solution; and $\mathrm{W}_{\mathrm{a}}(\mathrm{g})$ is the weight of the chelating fabric. It was found that the boron chelation detected in each experiment under the same conditions was slightly different. This may be due to the structure of the chelating fabric and the stirring effect. Even so, the error of the boron chelation was still less than $1.0 \%$, and the chelating results showed a good and reasonable trend with the chelating time.

The reusability and stability of the chelating fabric were tested through 10 cycles of chelation-elution operations. This series of operations was performed under shaking at $25^{\circ} \mathrm{C}$. For each cycle, the chelating fabric is immersed in $30 \mathrm{~mL}$ boron solution $(20.42 \mathrm{mg} / \mathrm{L})$ for $30 \mathrm{~min}$ for chelation, immersed in $15 \mathrm{~mL} \mathrm{HCl}$ solution $(0.1 \mathrm{M})$ for $15 \mathrm{~min}$ for elution, and then water washed for $5 \mathrm{~min}$, treated with $0.1 \mathrm{M} \mathrm{KOH}$ for $5 \mathrm{~min}$, and water washed again thoroughly to regenerate the chelating fabric for the next cycle. The elution time was sufficient for the release of the chelated boron. We confirmed that more than $98 \%$ of the boron was eluted within $5 \mathrm{~min}$. 
To evaluate the stability, the chelating fabrics were immersed in water, $0.1 \mathrm{M} \mathrm{HCl}$ and $0.1 \mathrm{M} \mathrm{KOH}$ solutions, respectively, at $80^{\circ} \mathrm{C}$ for $48 \mathrm{~h}$. The weights of chelating fabrics before and after immersion in these solutions were weighed to evaluate their stability.

\section{Results and Discussion}

\subsection{Preparation of GMA-Grafted Fabric}

The GMA-grafted fabric was used as a framework for the attachment of NMDG moieties to prepare a chelating fabric. The GMA-grafted fabric was prepared by a preirradiation grafting technique [35].

In the first step of preparation, the starting fabric is irradiated with gamma rays. Under irradiation, some $\mathrm{C}-\mathrm{H}$ and $\mathrm{C}-\mathrm{C}$ covalent bonds split into free radicals. In the amorphous phase, the radicals can re-bond to form crosslinked structures or small molecules. However, in the crystal phase, they are quite stable and can survive for several days at room temperature [37]. When the irradiated fabric comes in contact with the GMA monomers, the radicals can initiate the graft polymerization.

Table 1 summarizes the grafting conditions and properties of the resulting GMAgrafted fabric. The high grafting of $179.5 \%$ and the corresponding epoxy density of $4.52 \mathrm{mmol} / \mathrm{g}$ can be expected to yield a fabric with high chelating capacity. When each epoxy ring is converted to one NMDG moiety, fabric with a high chelating capacity of $2.40 \mathrm{mmol} / \mathrm{g}$ can be obtained. The GMA-grafted fabric with a high grafting of $179.5 \%$ has sufficient strength in both wet and dry states. This can be attributed to the high mechanical strength of PP in the PE/PP fibers. A degree of grafting higher than $200 \%$ can be obtained easily by changing the reaction conditions. However, the stability of the resulting chelating fabric decreases due to the separation of the graft phase from the fibers. After grafting, the fabric becomes stiff and somewhat hydrophilic.

Table 1. Grafting conditions and GMA-grafted fabric used in this study.

\begin{tabular}{|c|c|c|c|c|c|c|}
\hline \multicolumn{5}{|c|}{ Grafting Conditions } & \multicolumn{2}{|c|}{ Grafting Results } \\
\hline Starting fabric & $\begin{array}{l}\text { Preirradiation } \\
(k G y)\end{array}$ & Monomer * & $\begin{array}{l}\text { Temp. } \\
\left({ }^{\circ} \mathrm{C}\right)\end{array}$ & $\begin{array}{l}\text { Time } \\
(\mathrm{h})\end{array}$ & $\begin{array}{c}\text { Grafting } \\
(\%)\end{array}$ & $\begin{array}{l}\text { Epoxy density } \\
(\mathrm{mmol} / \mathrm{g})\end{array}$ \\
\hline $\mathrm{PE} / \mathrm{PP}$ & 24.0 & GMA & 40 & 4.0 & 179.5 & 4.52 \\
\hline
\end{tabular}

ment.

\subsection{Preparation of Chelating Fabric}

The chelating fabric was prepared by immersing the GMA-grafted fabric in an NMDG aqueous solution with different concentrations up to $40 \%$, which is close to the saturation concentration at room temperature. The reaction temperature was $80^{\circ} \mathrm{C}$ and the reaction time was $3 \mathrm{~h}$. No organic solvents were added to the reaction solution. Figure 1 shows the chelating capacity of the resulting fabrics as a function of the NMDG concentration. In the $40 \%$ NMDG solution, the chelating capacity reaches $1.74 \mathrm{mmol} / \mathrm{g}$, which corresponds to $58.4 \%$ conversion of the epoxy rings to NMDG moieties. Because of steric hindrance and side reactions, a large number of epoxy rings are not converted to the NMDG moieties [38]. Prolonging the reaction time to $24 \mathrm{~h}$ or increasing the reaction temperature to $100{ }^{\circ} \mathrm{C}$ had almost no effect on the further increase in conversion. Nevertheless, considering the trade-off between performance and cost, the chelating fabric with a chelating capacity of $1.74 \mathrm{mmol} / \mathrm{g}$ is still acceptable for practical use.

In Figure 1, a threshold concentration appears between 10 and 20\% concentrations. The chelating capacity is quite low at the 10\% NMDG concentration and increased linearly above the $20 \%$ concentration. The low reactivity in the low NMDG concentration solution is because of the low affinity of the fabric toward the NMDG solution. When the GMAgrafted fabric was immersed into the $10 \%$ NMDG solution, initially, it was slightly white and was not completely wetted by the solution. In contrast, in the solution with an NMDG concentration of more than $20 \%$, the GMA-grafted fabric was quickly wetted and 
completely swollen by the solution, indicating good affinity and reactivity between them. Increasing the NMDG concentration increases the possibility of contact between the NMDG molecules and epoxy rings, and decreases the polarity of the solution. This leads to an increased affinity between the solution and the fabric and thus increases the reactivity.

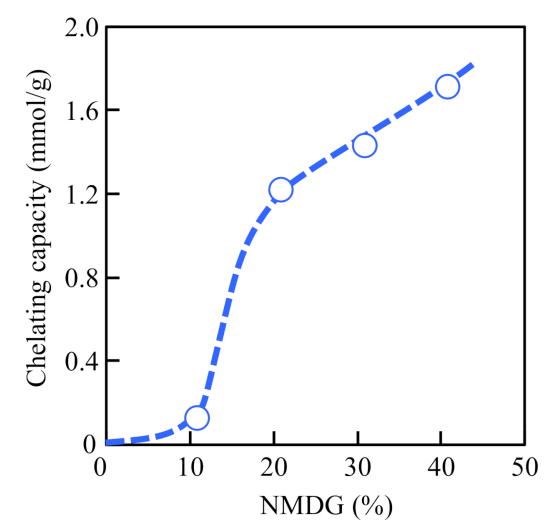

Figure 1. Effects of NMDG concentration in aqueous solution on chelating capacity of the resulting chelating fabrics. Reaction time, $3 \mathrm{~h}$; temperature, $80^{\circ} \mathrm{C}$; without organic solvents.

\subsection{Enhancing the Attachment Reaction by Surfactants}

We added surfactants to the NMDG solution to improve its affinity to the fabric. Three surfactants, cationic (OTBr), anionic (SDS), and non-ionic (POSM), were added at a concentration of $1.0 \%$ in $40 \%$ NMDG aqueous solutions. The reaction was controlled at $80^{\circ} \mathrm{C}$ for $3 \mathrm{~h}$. After adding the surfactants, the GMA-grafted fabric was fully wetted by the solutions quickly. As shown in Figure 2a, when there is no surfactant, the chelating capacity is $1.74 \mathrm{mmol} / \mathrm{g}$, and it increases to $1.85,2.00$, and $2.08 \mathrm{mmol} / \mathrm{g}$, with the addition of the surfactants of OTBr, SDS, and POSM, respectively. The increase in reactivity is caused by the improved affinity of the GMA-grafted fabric to the solution. The commercial Amberlite ${ }^{\circledR}$ IRA743 chelating resin has an NMDG moiety density of $0.70 \mathrm{mmol} / \mathrm{mL}$ and a water content of about $50 \%$, corresponding to a chelating capacity of about $1.9 \mathrm{mmol} / \mathrm{g}$ in the dry state [39]. The chelating capacity of $2.08 \mathrm{mmol} / \mathrm{g}$ of the resulting chelating fabric is close to that of the Amberlite ${ }^{\circledR}$ IRA743 chelating resin.
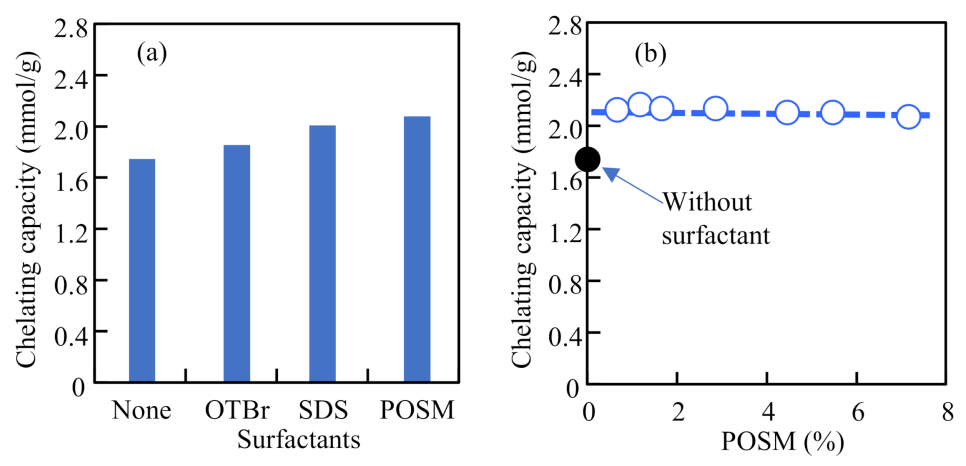

Figure 2. Effects of surfactants on the chelating capacity of the chelating fabric. NMDG aqueous solution, $40 \% ; 80^{\circ} \mathrm{C} ; 3$ h. (a) Effects of $1.0 \%$ surfactants of OTBr, SDS, and POSM. (b) Effects of POSM surfactant concentration.

Among the three surfactants, the addition of POSM resulted in the highest chelating capacity of $2.08 \mathrm{mmol} / \mathrm{g}$. Furthermore, POSM has excellent properties such as low toxicity and good solubility in water. Figure $2 \mathrm{~b}$ shows the effects of the POSM concentration on the chelating capacity. As expected, the chelating capacity is almost independent of the surfactant concentration. The critical micelle concentration (CMC) of POSM in water at 
room temperature is about $0.01 \%$, which is much lower than that used in this study. Even a small amount of surfactant (less than $0.5 \%$ ) can make the fabric well wetted by the solution. Therefore, the surfactant concentration used in this study is sufficient to enhance the affinity of the fabrics in solution [40].

\subsection{Accelerating the Attachment Reaction by Base and Acid Catalysts}

The attachment of NMDG onto the GMA-grafted fabric is an $\mathrm{SN}_{2}$ substitution reaction between the epoxy rings and secondary amine of NMDG [27,41,42]. Therefore, inorganic bases and acids can act as catalysts to accelerate the reaction. Figure 3 a shows that, at a low concentration of $10 \%$ NMDG solution, the chelating capacity for the reaction without the catalyst is only $0.13 \mathrm{mmol} / \mathrm{g}$, whereas by adding $\mathrm{KOH}$ and $\mathrm{HCl}$ it increases to 0.68 and $0.76 \mathrm{mmol} / \mathrm{g}$, respectively. However, when a high concentration of $40 \%$ NMDG solution was used, the chelating capacity for the system without the catalyst was $1.74 \mathrm{mmol} / \mathrm{g}$, and it slightly increased to 1.81 and $1.92 \mathrm{mmol} / \mathrm{g}$, respectively, when $\mathrm{KOH}$ and $\mathrm{HCl}$ were added. Thus, at high NMDG concentrations, the catalyst effects on the reaction are relatively low.
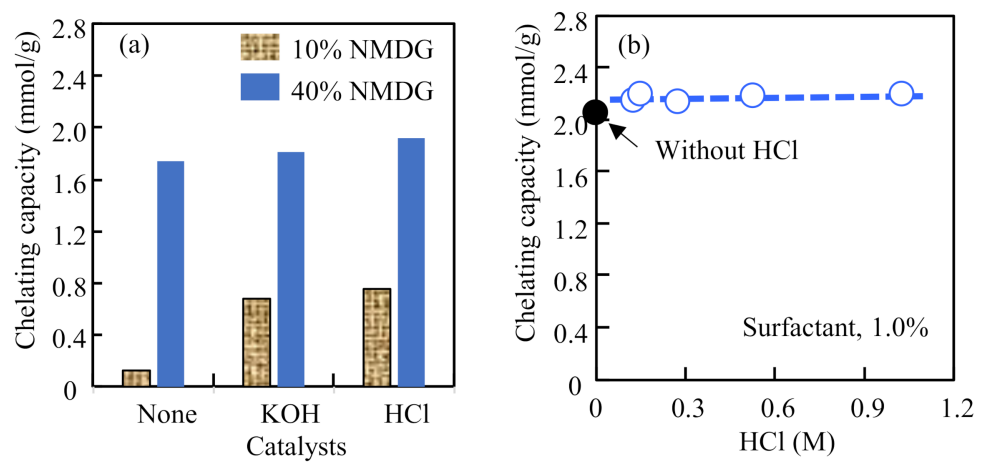

Figure 3. Effect of catalysts on chelating capacity of the chelating fabric. Reaction temperature, $80{ }^{\circ} \mathrm{C}$; time, 3 h. (a) NMDG concentration, $10 \%$ and $40 \%$ in aqueous solution; catalyst, $0.1 \mathrm{M}$. (b) Effect of $\mathrm{HCl}$ concentration. NMDG concentration, $40 \%$; POSM surfactant, $1.0 \%$.

$\mathrm{HCl}$ is a more effective catalyst than $\mathrm{KOH}$. Figure $3 \mathrm{~b}$ shows the effect of the $\mathrm{HCl}$ concentration on the chelating capacity. Here, $1.0 \%$ of the POSM surfactant was added to the reaction solution. As shown in Figure $3 b$, in the absence of $\mathrm{HCl}$, the chelating capacity is $2.04 \mathrm{mmol} / \mathrm{g}$. When $\mathrm{HCl}$ is added, it increases to $2.15-2.20 \mathrm{mmol} / \mathrm{g}$ and is almost independent of the $\mathrm{HCl}$ concentration. Thus, a low $\mathrm{HCl}$ concentration of $0.1 \mathrm{M}$ is sufficient to catalyze the reaction.

Scheme 3 shows the mechanism of reaction catalyzed by $\mathrm{KOH}$ and $\mathrm{HCl}$. Owing to the strain of the three-membered rings, the epoxy rings on the GMA-grafted fabric are highly reactive. In the $\mathrm{SN}_{2}$ substitution reaction between the epoxy rings and NMDG, the secondary amine of NMDG attacks the carbon of epoxy rings and forms a new fabric with NMDG moieties [27,33]. The NMDG moiety is usually attached to the less hindered terminal carbon of the epoxy ring due to steric effects. When $\mathrm{HCl}$ is used as a catalyst, the oxygen of the epoxy ring is protonated by the acid, thereby increasing the reactivity of NMDG to attack the carbon of the epoxy ring. Conversely, when $\mathrm{KOH}$ is the catalyst, the secondary amine of NMDG is activated by the hydroxide ion, which is more conducive for attacking the carbon of epoxy ring $[43,44]$. Here, the GMA-grafted fabric is a solid material that is insoluble. The attachment reaction of NMDG onto the GMA-grafted fabric is a solid-phase reaction or a heterogeneous reaction. Compared with the general solution reaction, the reaction of the GMA-grafted fabric with NMDG is more complex, and the reaction rate and conversion are relatively low. 


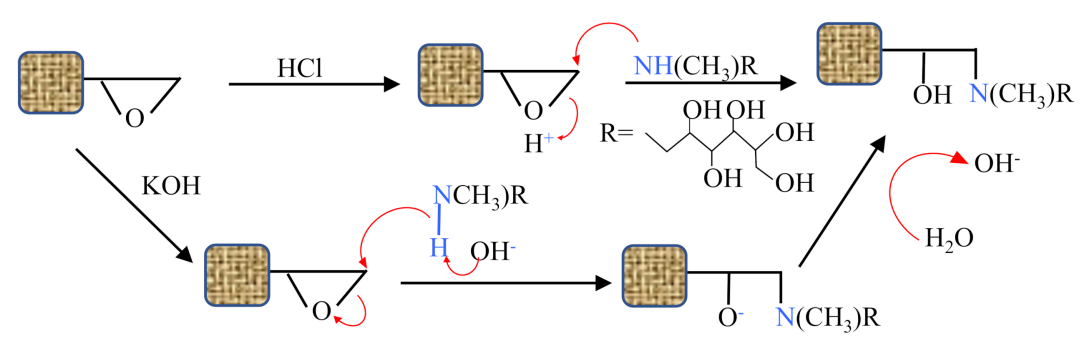

Scheme 3. Substitution reaction of GMA-grafted fabric with NMDG catalyzed by $\mathrm{HCl}$ and $\mathrm{KOH}$.

\subsection{Reaction Kinetics}

The reaction was confirmed to be enhanced by adding surfactants and catalysts to the reaction solutions. The reaction kinetics in the four conditions of the NMDG aqueous solution, (1) without any additives, (2) adding $\mathrm{HCl}$ as a catalyst, (3) adding POSM as a surfactant, and (4) adding both $\mathrm{HCl}$ and POSM, are summarized in Figure 4a. For comparison, the kinetics of the traditional attachment reaction in a 1,4-dioxane/water mixed solvent is shown in Figure $4 \mathrm{~b}$.
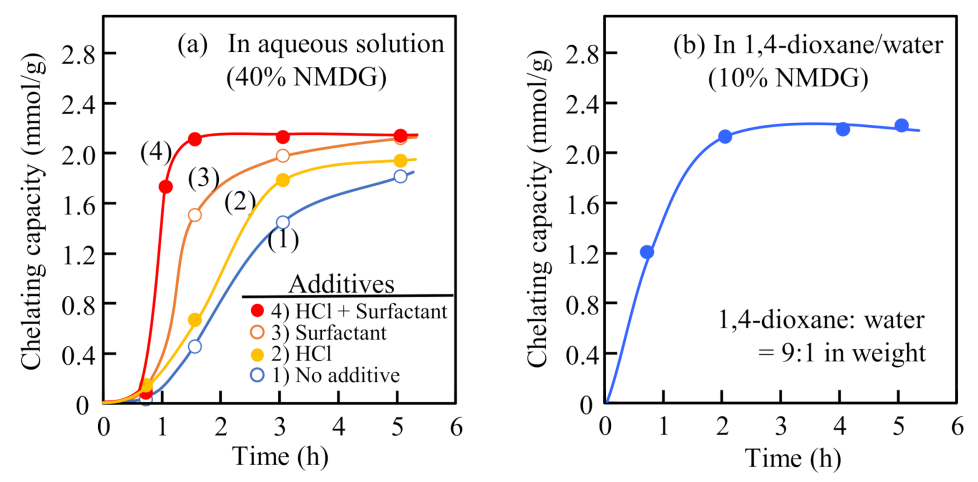

Figure 4. Kinetics of the reaction of GMA-grafted fabric in NMDG solution at $80{ }^{\circ} \mathrm{C}$. (a) In $40 \%$ NMDG aqueous solution, and (b) in 10\% NMDG 1,4-dioxane/water solution.

Figure 4 a shows that there is an initial induction period during which the reaction is quite slow for all four conditions. This is because of the relative hydrophobicity and microporous structure of the fabric, which makes the NMDG diffuse slowly into the GMAgrafted fabric. After the fabric is well wetted by the solution, the NMDG molecules diffuse into the fabric and react with the epoxy rings quickly. The chelating capacity increased dramatically and reached a plateau level.

The rate of the reaction increased when the $\mathrm{HCl}$ catalyst and surfactant were added. Without any additives, the reaction plateaus after $5 \mathrm{~h}$, whereas on adding both the catalyst and surfactant, the chelating capacity attains a high level of $2.0 \mathrm{mmol} / \mathrm{g}$ within $2 \mathrm{~h}$. The surfactant improves the affinity of the fabric to the solution, and $\mathrm{HCl}$ catalyzes the substitution reaction by protonation of the oxygen atoms on the epoxy rings [41]. For comparison, the kinetics of the traditional reaction using a mixed solvent of 1,4-dioxane and water is shown in Figure $4 \mathrm{~b}$. The chelating capacity increases linearly with the increasing reaction time and reaches a value of $2.0 \mathrm{mmol} / \mathrm{g}$ within $2 \mathrm{~h}$. No induction period was observed for this system. Consequently, the reaction in the aqueous solution containing the catalyst and surfactant is comparable to that in the solution with an organic solvent [36].

\subsection{Boron Chelation in Aqueous Solution}

Figure 5 a shows the kinetics of boron chelation of the chelating fabric in boron aqueous solutions with the initial concentration of 10,50 , and $100 \mathrm{mg} / \mathrm{mL}$. The chelating fabric with high chelating capacity of $2.15 \mathrm{mmol} / \mathrm{g}$ was used. The boron chelation is very fast, reaching a steady-state plateau within $20 \mathrm{~min}$. The higher the initial boron concentration of the aqueous solution, the higher is the boron chelating ability obtained by the chelating 
fabric. The boron chelation of the chelating fabric reaches $17.8 \mathrm{mg} / \mathrm{g}$ in the $100 \mathrm{mg} / \mathrm{L}$ solution, $12.0 \mathrm{mg} / \mathrm{g}$ in the $50 \mathrm{mg} / \mathrm{L}$ solution, and further reduced to $4.3 \mathrm{mg} / \mathrm{g}$ in the $10 \mathrm{mg} / \mathrm{L}$ solution. In the $10 \mathrm{mg} / \mathrm{L}$ solution, all the boron is captured by the chelating fabric, while in the $100 \mathrm{mg} / \mathrm{L}$ solution, the chelating fabric is saturated to bond with boron. The chelating kinetics of boron chelation is similar to the results reported by Ting et al., where the attachment reaction was performed in a 10\% 1,4-dioxane solution [45]. Therefore, the preparation of the chelating fabric without organic solvent is more environmentally friendly, and the resulted chelating fabric can be used to remove trace boron in drinking and irrigation water and effectively reduce boron concentration in wastewater.
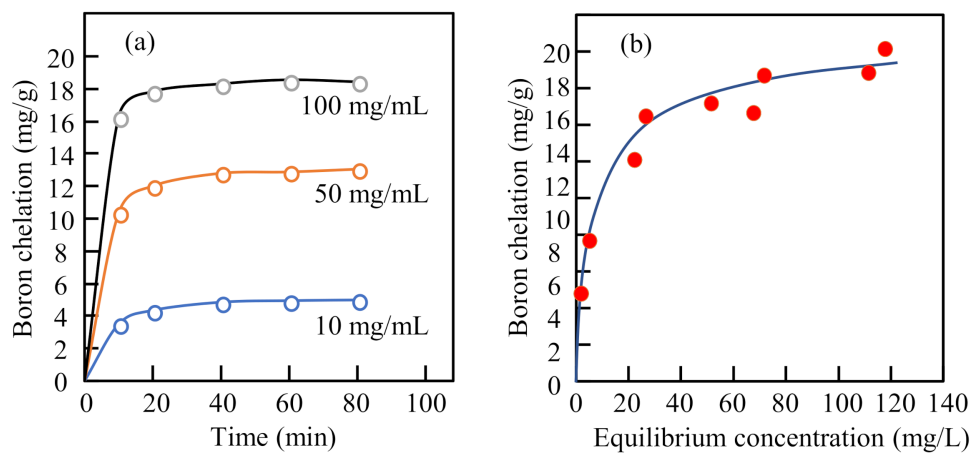

Figure 5. (a) Boron chelation kinetics of the chelating fabric in the initial concentrations of 10, 50, and $100 \mathrm{mg} / \mathrm{L}$ boron aqueous solution. (b) Relationship between boron chelation and equilibrium boron concentration in the remaining solution. Chelating time, $24 \mathrm{~h}$; temperature, $25^{\circ} \mathrm{C}$.

Figure $5 \mathrm{~b}$ shows the relationship between the boron chelation of the chelating fabric and the boron concentration of the remaining solution at $25^{\circ} \mathrm{C}$, recorded at a chelation time of $24 \mathrm{~h}$, which is sufficient to establish an equilibrium state. For a low equilibrium of boron chelation of $4.3 \mathrm{mg} / \mathrm{g}$, the equilibrium boron concentration in the remaining solution is too low to be accurately detected, indicating that the chelating fabrics can remove trace boron from water. In contrast, in the remaining solution with a boron concentration higher than $70 \mathrm{mg} / \mathrm{L}$, a high boron chelating ability of $18.3 \mathrm{mg} / \mathrm{g}$ or $1.69 \mathrm{mmol} / \mathrm{g}$ is reached. Considering the NMDG density $(2.15 \mathrm{mmol} / \mathrm{g})$ of the chelating fabric, it can be concluded that about $50 \%$ of NMDG moieties were bonded with boron to form the mono-chelated structures and the remaining 50\% were bonded in the form of bis-chelated structures (Scheme 2) [46,47].

\subsection{FTIR Characterization}

FTIR was used for characterization of the chelating fabrics before and after the boron chelation, the corresponding GMA-grafted fabric, and the starting nonwoven fabric. Figure 6 shows that the nonwoven fabric presents a simple spectrum because of the olefine chain of polyethylene. After grafting, the spectrum of the GMA-grafted fabric becomes complex and presents a strong peak around $1721 \mathrm{~cm}^{-1}$ assigned to the $\mathrm{C}=\mathrm{O}$ structure, and three peaks at 986,903 , and $839 \mathrm{~cm}^{-1}$ assigned to the epoxy rings. After the attachment reaction with NMDG, very broad and strong peaks around $3324 \mathrm{~cm}^{-1}$ (assigned to the $\mathrm{O}-\mathrm{H}$ bond) and $1053 \mathrm{~cm}^{-1}$ (assigned to $\mathrm{C}-\mathrm{O}$ and $\mathrm{C}-\mathrm{N}$ bonds) appear in the spectrum of the resulting chelating fabric. These results indicate that the GMA was grafted onto the fabric, and the chelating fabric was obtained by the attachment reaction of NMDG to the grafted fabric. The boron-chelated sample was obtained by immersing the chelating fabric (chelating capacity, $2.15 \mathrm{mmol} / \mathrm{g}$ ) in concentrated boron aqueous solution for $30 \mathrm{~min}$, followed by drying in oven at $60{ }^{\circ} \mathrm{C}$ for $24 \mathrm{~h}$. A new peak around $930 \mathrm{~cm}^{-1}$, assigned to asymmetric B-O stretching, can be observed on the curve of boron-chelated sample (Figure 6d) [22,48]. 


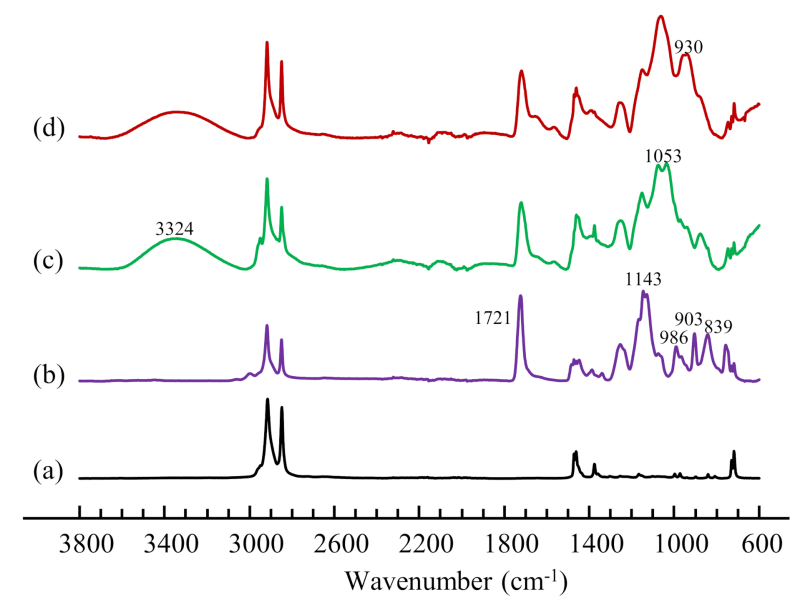

Figure 6. Fourier transform infrared spectrophotometer (FTIR) spectra of (a) nonwoven fabric, (b) GMA-grafted fabric, (c) chelating fabric prepared by attaching NMDG to GMA-grafted fabric, and (d) boron-chelated sample.

\subsection{Stability of the Chelating Fabric}

The chelating fabric is expected to be used repeatedly as a commercial chelating resin. Therefore, the chelating fabric should possess regeneration ability and high mechanical/chemical stability [49]. The regeneration of the chelating fabric includes $\mathrm{HCl}$ elution, $\mathrm{KOH}$ neutralization, and full water washing. As shown in Figure 7, 10 cycles of chelation-elution operations were performed, and the amount of boron chelated and eluted was determined.

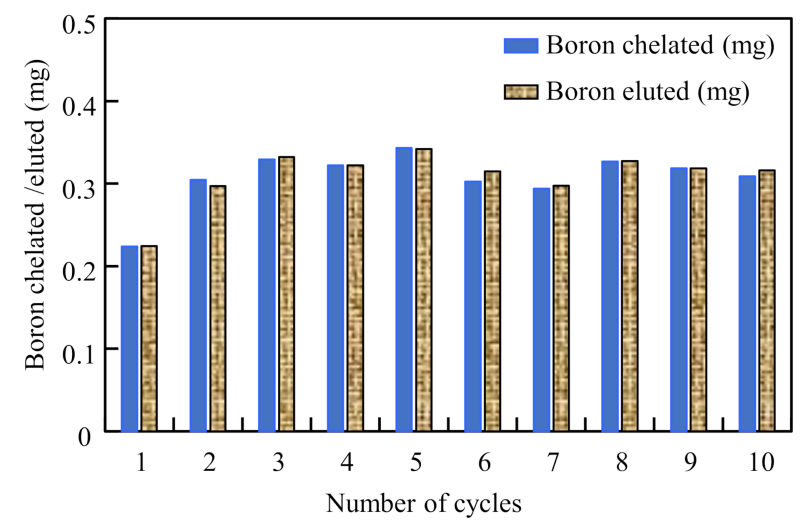

Figure 7. Stability of the chelating fabric under boron chelation-elution cycle test.

As shown in Figure 7, the amount of the chelated boron on the new chelating fabric at the first cycle was $0.23 \mathrm{mg}$, increased to more than $0.31 \mathrm{mg}$ after the second cycle, and then remained at a high level. The initial low chelating is due to the direct use of the dry chelating fabric without any pretreatment, where the boron diffusion is limited because the fabric is incompletely swollen. After the first cycle, the fabric is well wetted by the solution and the boron chelation is improved, resulting in a stable and high boron chelation.

In each chelation-elution cycle, the eluted boron is almost equal to that of the chelated boron. This indicates that the chelated boron can be completely eluted by the $0.1 \mathrm{M}$ $\mathrm{HCl}$ acid. According to the reaction shown in Scheme 1, Equation (3), at a low proton concentration, the reaction of boric acid with vicinal diol tends to form boron ester, while at a high proton concentration, boric acid tends to get released. During the elution of boric acid, the amine on the chelating fabric reacts with $\mathrm{HCl}$. Therefore, in addition to water washing, alkaline washing is needed to convert the amine [13].

After 10 cycles of chelation and elution, the chelating fabric was dried in an oven at $60{ }^{\circ} \mathrm{C}$ for $24 \mathrm{~h}$. It was found that the weight of the chelating fabric dropped from 55.2 to 
$53.1 \mathrm{mg}$ after the ten-cycle operations. This may be due to the strong shaking during the chelation-elution operations, which causes the fiber and the graft layer to separate from the fabric. Conversely, the chelating fabric was found to be very stable in water, $0.1 \mathrm{M} \mathrm{HCl}$, and $0.1 \mathrm{M} \mathrm{KOH}$ solutions at $80^{\circ} \mathrm{C}$ for $72 \mathrm{~h}$, and there was no change in weight under the above treatments. Therefore, the chelating fabric with high boron-chelating ability can be durable in acid elution solution and alkali washing solution at high temperature, and can be reused to remove boron from water.

\section{Conclusions}

A chelating fabric was successfully prepared by radiation grafting GMA onto a nonwoven fabric, followed by an attachment reaction with NMDG using an organic solvent-free process. Addition of surfactant enhances the affinity of the fabric to the solution, while acid catalyzes the substitution reaction. Both the reaction rate and the conversion of epoxy rings to NMDG moieties of the reaction in aqueous solution are comparable to those utilizing organic solution.

The boron chelation of the resulting chelating fabric in water is very fast, reaching steady-state chelation within $20 \mathrm{~min}$. The chelated boron can be quantitatively eluted with $0.1 \mathrm{M} \mathrm{HCl}$ solution within $5 \mathrm{~min}$. The boron chelation reaches a high level of $18.3 \mathrm{mg} / \mathrm{g}$ in the concentrated boron aqueous solution. Furthermore, the chelating fabric is chemically stable in acid and alkali solutions, showing good durability and reusability for at least 10 cycles of chelation-elution operations. Therefore, it can be concluded that the chelating fabric is promising for boron removal from water. In future work, we will further optimize the process for the mass production of the chelating fabric, and investigate the cost feasibility of actual use in industry.

Author Contributions: Conceptualization, H.H., J.C., and N.S.; methodology, formal analysis, and investigation, H.H., J.C., and H.A.; writing—original draft preparation, J.C.; writing—review and editing, J.C.; project administration, N.S. All authors have read and agreed to the published version of the manuscript.

Funding: This research was partly funded by the Japan Society for the Promotion of Science (JSPS) KAKENHI Grant Numbers JP17K00632 (Grant-in-Aid for Scientific Research (C)).

Institutional Review Board Statement: Not applicable.

Informed Consent Statement: Not applicable.

Data Availability Statement: Data is contained within the article.

Conflicts of Interest: The authors declare no conflict of interest.

\section{References}

1. Kochkodan, V.; Darwish, N.; Hilal, N. The Chemistry of Boron in Water; Elsevier: Amsterdam, The Netherlands, 2015.

2. Brdar-Jokanović, M. Boron toxicity and deficiency in agricultural plants. Int. J. Mol. Sci. 2020, 21, 1424. [CrossRef] [PubMed]

3. Wolska, J.; Bryjak, M. Methods for boron removal from aqueous solutions-A review. Desalination 2013, 310, 18-24. [CrossRef]

4. Hilal, N.; Kim, G.; Somerfield, C. Boron removal from saline water, a comprehensive review. Desalination 2011, $273,23-35$. [CrossRef]

5. Guan, Z.; Lv, J.; Bai, P.; Guo, X. Boron removal from aqueous solutions by adsorption-A review. Desalination 2016, $383,29-37$. [CrossRef]

6. Xu, Y.; Jiang, J. Technologies for boron removal. Indus. Chem. Res. 2008, 47, 16-24. [CrossRef]

7. Samatya, S.; Tuncel, S.; Kabay, N. Boron removal from RO permeate of geothermal water by monodisperse poly (vinylbenzyl chloride-co-divinylbenzene) beads containing N-methyl-D-glucamine. Desalination 2015, 364, 75-81. [CrossRef]

8. Tu, K.; Long, D.; Allan, R. Boron removal by reverse osmosis membranes in seawater desalination applications. Separ. Purif. Tech. 2010, 75, 87-101. [CrossRef]

9. Isaacs-Paez, E.; Leyva-Ramos, R.; Jacobo-Azuara, A.; Martinez-Rosales, J.; Flores-Cano, J. Adsorption of boron on calcined AlMg layered double hydroxide from aqueous solutions. Mechanism and effect of operating conditions. Chem. Eng. J. 2014, 245, 248-257. [CrossRef]

10. Bıçak, N.; Özbelge, H.; Yilmaz, L.; Senkal, B. Crosslinked polymer gels for boron extraction derived from N-glucidol-N-methyl-2hydroxypropyl methacrylate. Macromol. Chem. Phys. 2000, 201, 577-584. [CrossRef] 
11. Köse, D.A.; Zümreoglu-Karan, B. Complexation of boric acid with vitamin C. New J. Chem. 2009, 33, 1874-1881. [CrossRef]

12. Manjunatha, R.; Gerbec, J.; Shimizu, F.; Chmelka, B. Nanoscale surface compositions and structures influence boron adsorption properties of anion exchange resins. Langmuir 2019, 35, 15661-15673. [CrossRef]

13. Kamcev, J.; Taylor, M.; Shin, D.; Jarenwattananon, N.; Colwell, K.; Long, J. Functionalized porous aromatic frameworks as high-performance adsorbents for the rapid removal of boric acid from water. Adv. Mater. 2019, 31, 1808027. [CrossRef]

14. Wang, L.; Qi, T.; Gao, Z.; Zhang, Y.; Chu, J. Synthesis of N-methylglucamine modified macroporous poly(GMA-co-TRIM) and its performance as a boron sorbent. React. Funct. Polym. 2007, 67, 202-209. [CrossRef]

15. Ting, T.; Nasef, M.; Hashim, K. Tuning N-methyl-D-glucamine density in a new radiation grafted poly (vinyl benzyl chloride)/nylon-6 fibrous boron-selective adsorbent using the response surface method. RSC Adv. 2015, 5, 37869-37880. [CrossRef]

16. Wei, Y.T.; Zheng, Y.M.; Chen, J.P. Functionalization of regenerated cellulose membrane via surface-initiated atom transfer radical polymerization for boron removal from aqueous solution. Langmuir 2011, 27, 6018-6025. [CrossRef]

17. Kang, J.; Tang, Y.; Gao, S.; Liu, L. One-dimensional controllable crosslinked polymers grafted with N-methyl-D-glucamine for effective boron adsorption. New J. Chem. 2018, 42, 11334-11340. [CrossRef]

18. Sabarudin, A.; Oshita, K.; Oshima, M.; Motomizu, S. Synthesis of cross-linked chitosan possessing N-methyl-d-glucamine moiety (CCTS-NMDG) for adsorption/concentration of boron in water samples and its accurate measurement by ICP-MS and ICP-AES. Talanta 2005, 66, 136-144. [CrossRef]

19. Xiao, B.; Zhang, Y.; Wang, Y.; Jiang, G.; Liang, M.; Chen, X.; Long, G. A fractal model for Kozeny-Carman constant and dimensionless permeability of fibrous porous media with roughened surfaces. Fractals 2019, 27, 1950116. [CrossRef]

20. Gu, J.; Xiao, P.; Chen, P.; Zhang, L.; Wang, H.; Dai, L.; Song, L.; Huang, Y.; Zhang, J.; Chen, T. Functionalization of biodegradable PLA nonwoven fabric as superoleophilic and superhydrophobic material for efficient oil absorption and oil/water separation. ACS Appl. Mater. Interfaces 2017, 9, 5968-5973. [CrossRef]

21. Recepoğlu, Y.; Kabay, N.; Ipek, I.; Arda, M.; Yüksel, M.; Yoshizuka, K.; Nishihama, S. Packed bed column dynamic study for boron removal from geothermal brine by a chelating fiber and breakthrough curve analysis by using mathematical models. Desalination 2018, 437, 1-6. [CrossRef]

22. Nallappan, M.; Nasef, M.; Ting, T.; Ahmad, A. An optimized covalent Immobilization of glucamine on electrospun nanofibrous poly (vinylidene fluoride) sheets grafted with oxirane groups for higher boron adsorption. Fibers Polym. 2018, 19, $1694-1705$. [CrossRef]

23. Nasef, M.; Güven, O. Radiation-grafted copolymers for separation and purification purposes, Status, challenges and future directions. Prog. Polym. Sci. 2012, 37, 1597-1656. [CrossRef]

24. Hayashi, N.; Chen, J.; Seko, N. Nitrogen-containing fabric adsorbents prepared by radiation grafting for removal of chromium from wastewater. Polymers 2018, 10, 744. [CrossRef]

25. Kodama, Y.; Barsbay, M.; Güven, O. Poly (2-hydroxyethyl methacrylate) (PHEMA) grafted polyethylene/polypropylene (PE/PP) nonwoven fabric by $\gamma$-initiation, Synthesis, characterization and benefits of RAFT mediation. Radia. Phys. Chem. 2014, 105, 31-38. [CrossRef]

26. Dong, Z.; Zhao, L. Covalently bonded ionic liquid onto cellulose for fast adsorption and efficient separation of Cr (VI), Batch, column and mechanism investigation. Carbohyd. Polym. 2018, 189, 190-197. [CrossRef]

27. Muzammil, E.; Khan, A.; Stuparu, M. Post-polymerization modification reactions of poly (glycidyl methacrylate)s. RSC Adv. 2017, 7, 55874-55884. [CrossRef]

28. Kimmins, S.; Wyman, P.; Cameron, N. Amine-functionalization of glycidyl methacrylate-containing emulsion-templated porous polymers and immobilization of proteinase K for biocatalysis. Polymer 2014, 55, 416-425. [CrossRef]

29. Chen, J.; Asano, M.; Yamaki, T.; Yoshida, M. Preparation and characterization of chemically stable polymer electrolyte membranes by radiation-induced graft copolymerization of four monomers into ETFE films. J. Membr. Sci. 2006, 269, 194-204. [CrossRef]

30. Darwish, N.B.; Kochkodan, V.; Hilal, N. Microfiltration of micro-sized suspensions of boron-selective resin with PVDF membranes. Desalination 2017, 403, 161-171. [CrossRef]

31. Ehlers, J.; Rondan, N.; Huynh, L.; Pham, H.; Marks, M.; Truong, T. Theoretical study on mechanisms of the epoxy- amine curing reaction. Macromolecules 2007, 40, 4370-4377. [CrossRef]

32. Jouyandeh, M.; Shabanian, M.; Khaleghi, M.; Paran, S.; Ghiyasi, S.; Vahabi, H.; Formela, K.; Puglia, D.; Saeb, M. Acid-aided epoxy-amine curing reaction as reflected in epoxy $/ \mathrm{Fe}_{3} \mathrm{O}_{4}$ nanocomposites, Chemistry, mechanism, and fracture behavior. Prog. Org. Coat. 2018, 125, 384-392. [CrossRef]

33. Mijovic, J.; Fishbain, A.; Wijaya, J. Mechanistic modeling of epoxy-amine kinetics. 1. Model compound study. Macromolecules 1992, 25, 979-985. [CrossRef]

34. Ikeda, K.; Umeno, D.; Saito, K.; Koide, F.; Miyata, E.; Sugo, T. Removal of boron using nylon-based chelating fibers. Indus. Eng. Chem. Res. 2011, 50, 5727-5732. [CrossRef]

35. Seko, N.; Ninh, N.; Tamada, M. Emulsion grafting of glycidyl methacrylate onto polyethylene fiber. Rad. Phys. Chem. 2010, 79, 22-26. [CrossRef]

36. Hoshina, H.; Seko, N.; Ueki, Y.; Tamada, M. Synthesis of graft adsorbent with N-methyl-D-glucamine for boron adsorption. J. Ion Exch. 2007, 18, 236-239. [CrossRef] 
37. Forster, A.; Tsinas, Z.; Al-sheikhly, M. Effect of irradiation and detection of long-lived polyenyl radicals in highly crystalline ultra-high molar mass polyethylene (UHMMPE) fibers. Polymers 2019, 11, 924. [CrossRef]

38. Mora, A.S.; Tayouo, R.; Boutevin, B.; David, G.; Caillol, S. A perspective approach on the amine reactivity and the hydrogen bonds effect on epoxy-amine systems. Eur. Polym. J. 2020, 123, 109460. [CrossRef]

39. Mun, D.; Huynh, N.; Shin, S.; Kim, Y.; Kim, S.; Shul, Y.; Cho, J. Facile isomerization of glucose into fructose using anion-exchange resins in organic solvents and application to direct conversion of glucose into furan compounds. Res. Chem. Intermed. 2017, 43, 5495-5506. [CrossRef]

40. Sar, P.; Ghosh, A.; Scarso, A.; Saha, B. Surfactant for better tomorrow, applied aspect of surfactant aggregates from laboratory to industry. Res. Chem. Intermed. 2019, 45, 6021-6041. [CrossRef]

41. Eddingsaas, N.; Vandervelde, D.; Wennberg, P. Kinetics and products of the acid-catalyzed ring-opening of atmospherically relevant butyl epoxy alcohols. J. Phys. Chem. A 2010, 114, 8106-8113. [CrossRef]

42. Stropoli, S.; Elrod, M. Assessing the potential for the reactions of epoxides with amines on secondary organic aerosol particles. J. Phys. Chem. A 2015, 119, 10181-10189. [CrossRef]

43. Innocenzi, P.; Kidchob, T.; Yoko, T. Hybrid organic-inorganic sol-gel materials based on epoxy-amine systems. J. Sol-Gel Sci. Techn. 2005, 35, 225-235. [CrossRef]

44. Blank, W.; He, Z.; Picci, M. Catalysis of the epoxy-carboxyl reaction. J. Coat. Tech. 2002, 74, 33-41. [CrossRef]

45. Ting, T.; Nasef, M. Modification of polyethylene-polypropylene fibers by emulsion and solvent radiation grafting systems for boron removal. Fibers. Polym. 2017, 18, 1048-1055. [CrossRef]

46. Joshi, M.; Chalumot, G.; Kim, Y.; Anderson, J. Synthesis of glucaminium-based ionic liquids and their application in the removal of boron from water. Chem. Commun. 2012, 48, 1410-1412. [CrossRef]

47. Joshi, M.; Steyer, D.; Anderson, J. Evaluating the complexation behavior and regeneration of boron selective glucaminium-based ionic liquids when used as extraction solvents. Anal. Chim. Acta 2012, 740, 66-73. [CrossRef]

48. Akan, Z.; Demiroglu, H.; Avcibasi, U.; Oto, G.; Ozdemir, H.; Deniz, S.; Basak, A.S. Complexion of Boric Acid with 2-Deoxy-Dglucose (DG) as a novel boron carrier for BNCT. Med. Sci. Discov. 2014, 1, 65-71. [CrossRef]

49. Wang, B.; Guo, X.; Bai, P. Removal technology of boron dissolved in aqueous solutions-a review. Coll. Surf. A Phys. Eng. Asp. 2014, 444, 338-344. [CrossRef] 